\title{
The development situation of biomass gasification power generation in China
}

\author{
Zhaoqiu Zhou, Xiuli Yin, Jie Xu, Longlong Ma* \\ CAS Key Laboratory of Renewable Energy and Gas Hydrate, Guangzhou Institute of Energy Conversion, Chinese Academy of Sciences, Guangzhou 510640, China
}

\section{H I G H L I G H T S}

- Biomass gasification power generation of $2 \mathrm{~kW}-2 \mathrm{MW}$ has wide utilization in China.

- 5.5 MW biomass IGCC demonstration plant has maximum power efficiency of up to $30 \%$.

- Biomass power generation is facing a serious challenge due to biomass cost increase.

\section{A R T I C L E I N F O}

\section{Article history:}

Received 4 July 2011

Accepted 24 May 2012

Available online 19 July 2012

\section{Keywords:}

Biomass gasification

Power generation

Development situation

\begin{abstract}
A B S T R A C T
This work presents the development situation of biomass gasification power generation technology in China and analyzes the difficulty and challenge in the development process. For China, a large agricultural country with abundant biomass resources, the utilization of biomass gasification power generation technology is of special importance, because it can contribute to the electricity structure diversification under the present coal-dominant electricity structure, ameliorate the environmental impact, provide energy to electricity-scarce regions and solve the problems facing agriculture. Up to now, China has developed biomass gasification power generation plants of different types and scales, including simple gas engine-based power generation systems with capacity from several kW to $3 \mathrm{MW}$ and integrated gasification combined cycle systems with capacity of more than $5 \mathrm{MW}$. In recent years, due to the rising cost of biomass material, transportation, manpower, etc., the final cost of biomass power generation has increased greatly, resulting in a serious challenge in the Chinese electricity market even under present preferential policy for biomass power price. However, biomass gasification power generation technology is generally in accord with the characteristics of biomass resources in China, has relatively good adaptability and viability, and so has good prospect in China in the future. (c) 2012 Elsevier Ltd. All rights reserved.
\end{abstract}

\section{Significance of biomass gasification power generation in China}

Even as an emerging biomass power generation technology in China, biomass gasification power generation technology has been extensively studied (Yin et al., 2002; Wu et al., 2002; Liao et al., 2007; Ma et al., 2008; Wu et al., 2009), widely applied and well equipped. It is a promising biomass technology aiming at efficient and clean utilization: first converting carbonaceous material into combustible gas which contains $\mathrm{CO}, \mathrm{H}_{2}$, and $\mathrm{CH}_{4}$, in the gasification sector by employing a thermal-chemical method and then using the gas to drive turbines or engines for power generation in the electricity sector. Biomass gasification power generation is quite a unique biomass utilization technique that can be distinguished from others through the following characteristics: a) Strong adaptability—it has the ability to tackle

\footnotetext{
* Corresponding author. Tel.: +86 2087057673.

E-mail address: mall@ms.giec.ac.cn (L. Ma).
}

many kinds of biomass feed materials such as straw, rice husk, sawdust, bagasse and so on, making it suitable for the widely distributed biomass resources in China, a large agricultural country. b) Better flexibility - it is free to choose suitable subsequent electricity equipment according to its scale, because different equipment, such as gas engines, gas turbines, exhaust heat boilers and steam turbines, can be integrated into its electricity sector. This characteristic grants it rational electricity generating efficiency and commercial acceptability even at a relatively small scale. In addition, there is no high pressure involved in the process, which allows simpler equipment and easier operation. c) More cleanliness_biomass is itself a kind of renewable resource, which could help to reduce the emission of pollutants such as $\mathrm{CO}_{2}$ and $\mathrm{SO}_{2}$ effectively. It is important to note that the gasification technology could help further reduction of the emission of $\mathrm{NO}_{x}$, because all the gasification processes take place at relatively low temperatures which inhibit the formation of $\mathrm{NO}_{x}$.

To develop biomass gasification power generation technology in China is considered to be important since there are other special significances. 


\subsection{Reducing coal-based electricity share in energy mix and ameliorating air pollution}

Though short of oil and natural gas, China is the largest coal producer and consumer in the world, with a proportion of coalbased electricity more than $70 \%$ in national electricity consumption, which is double the world average. This coal-dominant electricity structure not only results in shortage of coal stockpiles and difficulties of coal transportation, but also brings negative impact on the environment in China. Though this dominant position of coal-based electricity is not likely to be improved much in a short term, as a utilization of clean energy which is expected to effect a sharp reduction in the emission of pollutants in the power generation process, biomass gasification power generation technology has its strategic value both in electricity structure diversification and environment protection.

\subsection{Providing energy for electricity-scarce regions}

Rapid economic and social development underpinned the strong growth in electricity demand. Although the power supply has been increasing year after year, it still cannot meet production needs and household use. As power rationing happens from time to time, electricity shortage poses a serious problem especially in backward areas far from the grid. On the other hand, China abounds in biomass resources, of which most are agricultural wastes distributed in the electricity-scarce regions. Compared with traditional coal-based electricity, biomass-based electricity needs only smaller units and lower investment, which not only is suitable to the widely dispersed resources but also meets the energy demand in China. It would be a feasible way to ameliorate the power demand-and-supply tension to establish several biomass power stations in some relatively centralized areas according to the local resource situation. The power generated would be provided to the consumers directly, as well as to the grid.

\subsection{Solving some environmental and energy supply problems in rural areas}

As an agricultural country, China has an annual output of crop stalks of nearly 700 million tons. Biomass, especially firewood and crop stalks, has been used as a kind of traditional energy in the countryside for a long time to warm and cook. However, the traditional way there to utilize biomass is through direct combustion in the kitchen, which not only results in low combustion efficiency (10\%), but involves strenuous labor and insalubrity. In some regions, extensive deforestation has destroyed the local ecological system, leading to more problems such as water and soil loss, soil degradation, desertification, etc. In contrast, along with the development of rural economy and improvement of living quality, people in the relatively wealthy rural parts prefer energy with high quality and cleanliness, which makes the fossil fuel market expand rapidly whereas lots of crop stalks are left over as waste in rural areas. In every harvest season, plenty of crop stalks are burnt in the open, resulting in not only massive biomass resource wasting, but also severe air pollution. In this case, biomass gasification power generation would be a good maneuver to solve such problems of countryside, agriculture and farmers, for it can provide rural energy, improve rural energy mix, subdue environmental pollution, and create more job opportunities, as well as boost the rural economy. In view of the fact that there is an idle population of about 150 million persons available as labor force in rural areas, biomass gasification power generation development can provide jobs for the surplus rural laborers and increase their income. For example, a biomass gasification power station of $1 \mathrm{MW}$ capacity needs about 30 workers presently, increasing their annual income by about 30 thousand RMB personally. It should be a good way to solve the problems facing agriculture, rural areas and farmers to some extent by developing the technology widely throughout China.

\section{Overview of biomass gasification power generation development in China}

Usually, for power generation, fuel gas produced from gasification process may be combusted in a gas-fired boiler to drive steam turbine generators, or led directly to gas engine generators or gas turbine generators. Currently, biomass gasification power generation technologies developed in China include the following two: a) small- and medium-scale biomass gasification power generation systems, generating power by a simple gas engine system with capacity from several $\mathrm{kW}$ to $3 \mathrm{MW}$ and b) large-scale biomass gasification power generation system, employing a subsidiary turbine generator driven by heat recovery steam based on the gas engine power generator to form an integrated gasification combined cycle system with capacity of more than $5 \mathrm{MW}$.

\subsection{Small- and medium-scale biomass gasification power generation system}

Most of small- and medium-scale biomass gasification power generation systems in China are mainly composed of a gasification sector and a power generation sector based on a gas engine, with scale varying from several $\mathrm{kW}$ to $3 \mathrm{MW}$. The scale of such a system is relatively small and the structure is simple.

The small ones with capacities less than $200 \mathrm{~kW}$ mainly adopt down-draft fixed bed for a gasifier which has low-tar outlets and simple and efficient purifiers, and usually fed with lump biomass materials. Fig. 1 shows a system with an efficiency of about $15 \%$. With higher capacities of 200-3000 kW, medium-scale biomass gasification power generation systems usually adopt bubbling fluidized beds or circulating fluidized beds for gasifiers; meanwhile a more complicated purifying system could be employed. Fig. 2 shows a system with an efficiency of about $17 \%$. The current gas engine used for this system is usually reformed from diesel engine, such as Type 6250 gas engine generator which was reformed by Chongqing Hongyan International-Combustion Company for low calorific gas with specification in Table 1 .

The research on gasification power generation with rice husk as feedstock started in the early 1960s in China, and progress has been made through these decades. Nowadays, small- or mediumscale biomass gasification power generation systems employing fixed beds or fluidized beds, are practically applied in China. The unit capacity is from $2 \mathrm{~kW}$ to $2 \mathrm{MW}$, with the power generating efficiency ranging 10-20\%. Among the companies and institutes in this field, Hefei Tianyan Green Energy Development Co., Ltd. (Tianyan) and Guangzhou Institute of Energy Conversion (GIEC) are outstanding due to their application programs. More details are as follows.

a) Tianyan has a rapid development in the application of biomass gasification power generation. Its biomass gasification gas engine

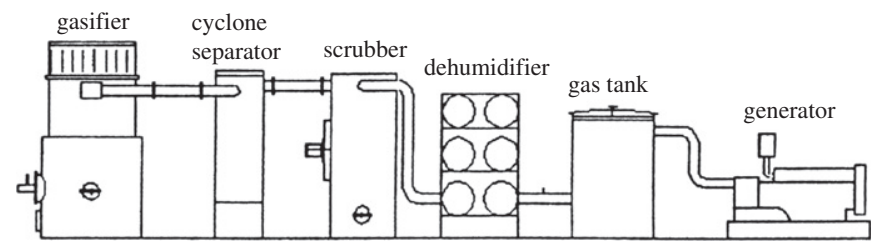

Fig. 1. Small-scale biomass gasification power generation system. 


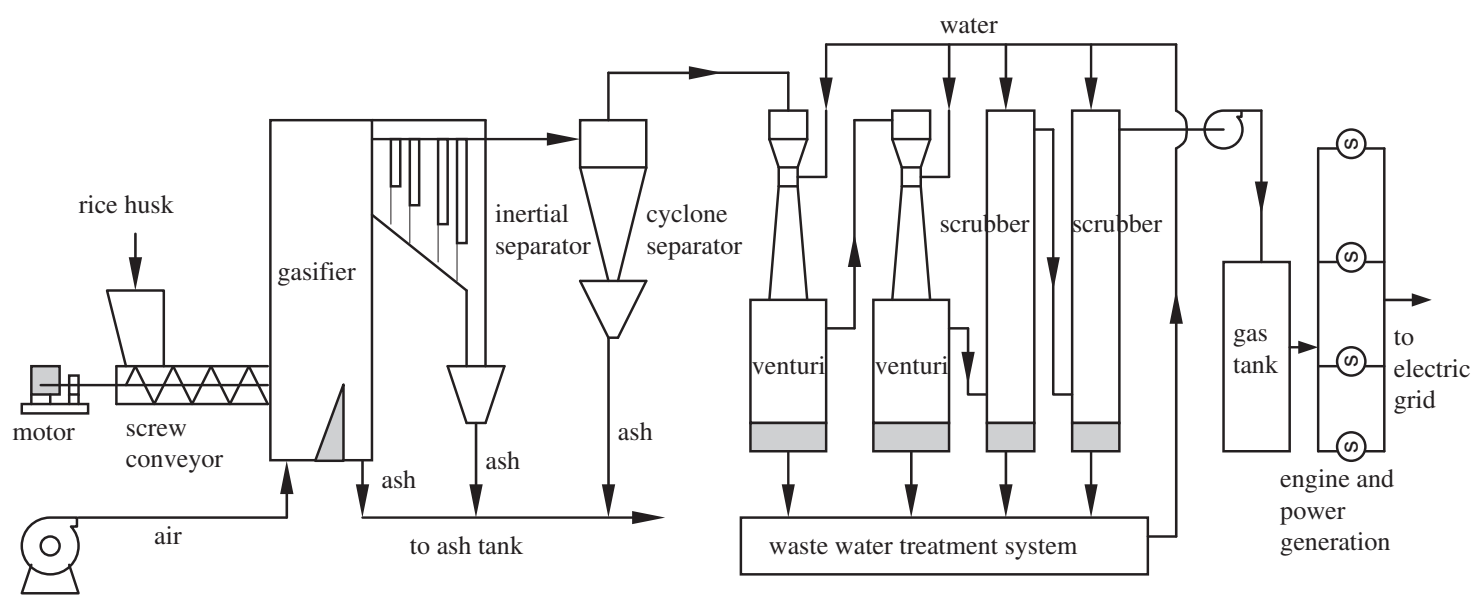

Fig. 2. Medium-scale biomass gasification power generation system.

Table 1

Technological parameters of Type 6250 gas engine generator for low calorific gas. ${ }^{\text {a }}$

\begin{tabular}{llll}
\hline Type & 6250 & Tolerated $\mathrm{H}_{2}$ fraction \\
Rated power & $200 \mathrm{~kW}$ & Tolerated tar content & $14 \%$ \\
Rotate speed & $750 \mathrm{rpm}$ & Gas consumption & $100 \mathrm{mg} / \mathrm{N} \mathrm{m}^{3}$ \\
Maximum power tested in $12 \mathrm{~h}$ & $221 \mathrm{~kW}$ & Thermal efficiency & $3.76 \mathrm{~N} \mathrm{~m}^{3} / \mathrm{kWh}^{26.5 \%}$ \\
Piston movement volume & $88.2 \mathrm{~L}$ & Exhaust temperature & $500{ }^{\circ} \mathrm{C}$ \\
Compression ratio & 9.0 & Lubricating oil pressure & $0.45 \mathrm{Mpa}$ \\
Required lowest heating value of gas & $4000 \mathrm{~kJ} / \mathrm{N} \mathrm{m}^{3}$ & Gas intake type & Self-sucking \\
\hline
\end{tabular}

a From Chongqing Hongyan International-Combustion Company.

Table 2

Technological parameters of $200 \mathrm{~kW}$ biomass down-draft fixed bed gasification power generation system of Tianyan Ltd.

\begin{tabular}{llll}
\hline Biomass & Various agricultural and forestry residues & Biomass heating value & $14,000 \mathrm{~kJ} / \mathrm{kg}$ \\
Gasifier & Down-draft fixed bed & Power output & $200 \mathrm{~kW}$ \\
Gas heating value & $\approx 4800 \mathrm{~kJ} / \mathrm{N} \mathrm{m}^{3}$ & Gas consumption & $\approx 780 \mathrm{~N} \mathrm{~m} \mathrm{~m}^{3} / \mathrm{h}$ \\
Biomass consumption & $\approx 360 \mathrm{~kg} / \mathrm{h}$ & Power efficiency & $15 \%$ \\
\hline
\end{tabular}

Table 3

Technological parameters of $1000 \mathrm{~kW}$ biomass fluidized bed gasification power generation system of Tianyan Ltd.

\begin{tabular}{|c|c|c|c|}
\hline Biomass & Various agricultural and forestry residues & Biomass heating value & $14,000 \mathrm{~kJ} / \mathrm{kg}$ \\
\hline Gasifier & Circulating fluidized bed & Power output & $1000 \mathrm{~kW}$ \\
\hline Gas heating value & $\approx 4800 \mathrm{~kJ} / \mathrm{N} \mathrm{m}^{3}$ & Gas consumption & $\approx 3700 \mathrm{~N} \mathrm{~m}^{3} / \mathrm{h}$ \\
\hline Biomass consumption & $\approx 1700 \mathrm{~kg} / \mathrm{h}$ & Power efficiency & $16 \%$ \\
\hline
\end{tabular}

generators have different capacities: $160 \mathrm{~kW}, 200 \mathrm{~kW}, 400 \mathrm{~kW}$, $600 \mathrm{~kW}, 800 \mathrm{~kW}, 1000 \mathrm{~kW}$, and the maximum output is over 1.4 MW. Two types of gasifiers have been adopted for gas production: down-draft fixed bed gasifier (TYG-900B) for gas engine unit capacity $200 \mathrm{~kW}$ and below, and fluidized bed gasifier (TYL-1800-TYL-4500) for $400 \mathrm{~kW}$ and above. The specification can be found in Tables 2 and 3. Up to now, there are more than ten biomass gasification power generation programs established by Tianyan, which are mostly of 200-600 kW. Tianyan's technologies have been exported to Japan, Thailand, Italy, etc.

b) GIEC has developed the first circulating fluidized bed biomass gasification power generation system in China. Earlier, by adopting reformed diesel engines, the single-machine capacity could only reach $200 \mathrm{~kW}$; now it reaches $500 \mathrm{~kW}$. The increase of total capacity of the system is achieved by parallel operation of several machines. The small- and medium-scale biomass gasification power generation systems developed by GIEC are suitable for illumination in the countryside, forest farms, and ranches or industrial use in small-sized factories. It can also provide power for production processes from agricultural and forest residues, such as leftovers of furniture factories or paper mills, or husk of rice mills. The electricity generated is considered to be stable because it is provided directly to the consumers, rid of the negative effects of the grid. Besides, a win-win situation is created by both utilizing the wastes and reducing the power price. Until now, more than 20 programs have been established by GIEC, with capacities ranging mainly from $800 \mathrm{~kW}$ to $1000 \mathrm{~kW}$. This technology has been exported to Thailand, Myanmar, Laos, etc., and is now the most extensively used smalland medium-scale biomass gasification power generation system. The specifications can be found in Table 4 .

As the main biomass material of China in the long term, agricultural waste is not only widely dispersed and difficult to gather and transport, but also seasonally unstable and susceptible to the crops scale. Therefore the scale of biomass gasification power generation should be carefully chosen according to material supply for the cost control. In China, a relatively small-scale system would be 
Table 4

Technological parameters of medium and small biomass gasification power generation systems developed by GIEC.

\begin{tabular}{|c|c|c|c|}
\hline Biomass & Various agricultural and forestry residues & Power output & $200-1200 \mathrm{~kW}$ \\
\hline Gasifier & Circulating fluidized bed & Annual runtime & $6000 \mathrm{~h} / \mathrm{yr}$ \\
\hline Gas heating value & $\approx 5000 \mathrm{~kJ} / \mathrm{N} \mathrm{m}^{3}$ & Power efficiency & $15-20 \%$ \\
\hline Biomass consumption & $1.2-1.5 \mathrm{~kg} / \mathrm{kWh}$ (wood sawdust), $1.6-1.8 \mathrm{~kg} / \mathrm{kWh}$ (rice, husk, straw) & Longtime running average load & $85 \%$ of designed value \\
\hline
\end{tabular}

more appropriate in this period. Comparing to other small- or medium-scale power generation systems with traditional fuels, biomass gasification power generation technology is more efficient and flexible. This advantage gives it a bright prospect for development and application in China. However, the gas engine most commonly employed in the system has some shortcomings such as low singlemachine capacity and low efficiency. It is imperative to develop a low calorific gas engine with higher capacity and efficiency. Furthermore, the ash formed in the power generation process still remains underutilized, inhibiting further application of the system. How to make full use of the ash is another important factor to enhance the benefit of this system.

\subsection{Large-scale biomass gasification power generation system}

In order to promote efficiency, the exhaust heat boiler and steam turbine have been integrated into the biomass gasification power generation system to form a biomass integrated gasification combined cycle (IGCC) system. In this system, electricity is generated first by combustion of the gas in a gas engine or gas turbine unit as mentioned above, and then by the exhaust heat boiler and steam turbine unit. The Rankine and Brayton cycles are coupled together for step-wise utilization of energy. But such a system is still small compared to the traditional energy system. As an advanced technology, IGCC has gained great attention since 1990 in virtue of its high efficiency (about 30-40\%), and has been studied first in some developed countries based on the gas turbine system (De Lange, 1998; Keith et al., 1998; ESPOO, 2002; Krister et al., 2004). Up to now, however, IGCC is still in pilot mode due to the immature key technology and high cost.

Capital and technological problems exist in China to develop the same biomass IGCC systems as some other countries. According to the different parts for electricity generation from gas, there are two technological pathways in the IGCC system: gasifier-gas enginesteam turbine and gasifier-gas turbine-steam turbine. Under the support of 863 national programs in China, GIEC developed its own high-efficient biomass integrated gasification combined cycle system with moderate scale, which has been proven to be economically feasible. This system includes a large-scale circulating fluidized bed, a large capacity low calorific gas engine, and a subsidiary exhaust heat utilization system, and all the equipment are manufactured in China. The maximum electrical efficiency of this system is up to $30 \%$, showing similar performance compared with those of foreign advanced technologies such as those of the Värnamo IGCC Demonstration Plant in Sweden (Krister et al., 2004), the THERMIE energy farm project in Italy (De Lange, 1998) and the ARBRE project in the UK (Keith et al., 1998), but needs only about $2 / 3$ of the investment and half the operation cost. This technology was utilized to establish a "5.5 MW biomass integrated gasification combined cycle program" in 2005, more details in Table 5.

As a technology demonstration pilot, this power plant has some characteristics:

a) Electricity efficiency improves a lot under a low investment. The maximum electricity efficiency is up to $30 \%$, showing more technological and economical advantages than small-sized coalbased power generation systems. The good cost performance ratio
Table 5

Technological parameters designed for 5.5 MW biomass IGCC plant by GIEC.

\begin{tabular}{ll}
\hline Items & Value \\
\hline Capacity & $5.5 \mathrm{MW}$ \\
Annual power output & $27,500,000 \mathrm{kWh}$ \\
Biomass consumption & $27,500 \mathrm{t} / \mathrm{yr}$ \\
Biomass & Rice husk, straw, wood sawdust, peanut hull \\
Generating cost & $0.28 \mathrm{RMB} / \mathrm{kWh}$ (excluding depreciation) \\
Power efficiency & $28-30 \%$
\end{tabular}

Table 6

Technological parameters of Type 8300 gas engine generator.

\begin{tabular}{ll}
\hline Items & Value \\
Type & 8300 \\
Cylinder number & 8 \\
Rated power & $400 \mathrm{~kW}$ \\
Rotation speed & $500 \mathrm{rpm}$ \\
Thermal efficiency & $28 \%$ \\
Output voltage & $400 \mathrm{~V}$ \\
Output frequency & $50 \mathrm{~Hz}$ \\
Power factor & 0.85 \\
\hline
\end{tabular}

makes this system more commercially competitive. The system within $3-10 \mathrm{MW}$ is particularly suitable for application in China.

b) The biomass circulating fluidized bed gasifier of $18 \mathrm{MWth}$ developed in the project is the biggest one in China. The project reduces technological risk and cost considerably by adopting the gas engine generator instead of the gas turbine generator which is more technologically complex and difficult to manufacture, and adopting simple and reliable gas purifying technologies for low and medium temperatures instead of complex high temperature ones.

Type 8300 gas engine generator (Dai et al., 2004) was derived from this program, whose specification can be found in Table 6 . Fig. 3 gives the result of its power efficiencies under various loads. Along with loads increasing from zero, the efficiency increased rapidly, and reached its maximum when the loads reached $70 \%$. After that, the efficiency declined slightly with increase of loads. Compared with the Type 6250 gas engine generator with a capacity of $200 \mathrm{~kW}$ which was usually used before, type 8300 of $400 \mathrm{~kW}$ not only doubled the load, but also improved the efficiency by $6 \%$.

This IGCC system employed a steam turbine generator with a capacity of $1.5 \mathrm{MW}$ besides the gas engine generator with capacity of $4 \mathrm{MW}$. The specifications of exhaust heat boiler and steam turbine can be found in Table 7 .

An economical and efficient system is the crux of the future application. Therefore how to establish such a system by utilizing existing technology is a primary task of the researches in biomass gasification power generation.

\subsection{Key barriers to the development of biomass gasification power generation}

High biomass feedback cost, small capacity of power generation unit and tar problem exist in the development of biomass gasification power generation in China. 


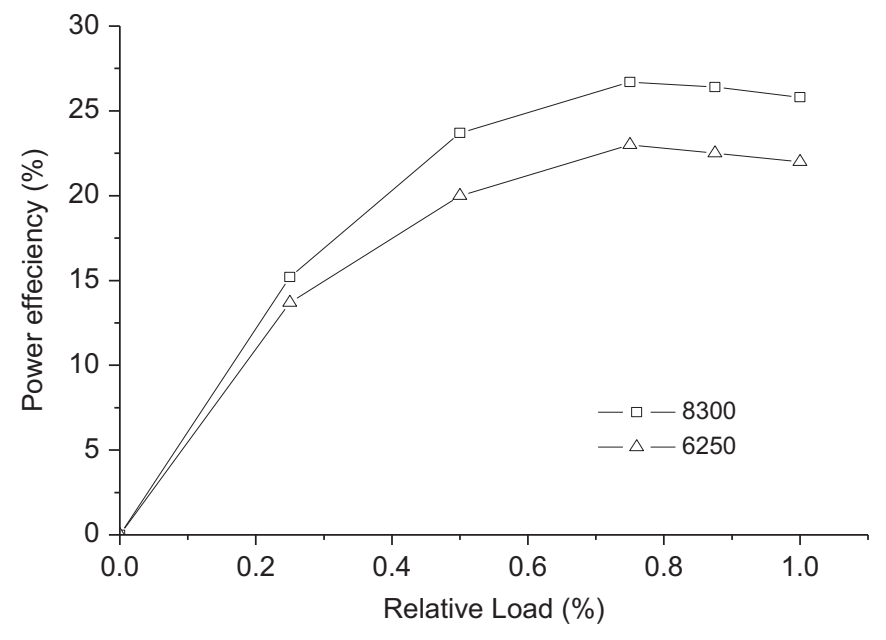

Fig. 3. Gas engine power efficiency under various loads.

Table 7

Technological parameters of exhaust heat boiler and steam turbine.

\begin{tabular}{llll}
\hline Exhaust heat boiler & \multicolumn{3}{c}{ Steam turbine } \\
\hline Evaporation & $10 \mathrm{t} / \mathrm{h}$ & Type & Condensing \\
Superheated steam temperature & $350^{\circ} \mathrm{C}$ & Rated power & $1500 \mathrm{~kW}$ \\
Superheated steam pressure & $1.35 \mathrm{MPa}$ & Rotation speed & $1500 \mathrm{rpm}$ \\
Feedwater temperature & $25^{\circ} \mathrm{C}$ & Steam consumption & $6.4 \mathrm{~kg} / \mathrm{kWh}$ \\
& & Steam pressure & $1.34 \mathrm{MPa}$ \\
& & Steam temperature & $310^{\circ} \mathrm{C}$ \\
& & Exhaust pressure & $0.0090 \mathrm{MPa}$ \\
\hline
\end{tabular}

Residues of agricultural and forestry production are the main biomass resources in China presently and will remain so in the future for a relatively long period of time. Due to their characteristics of low energy density, for example, the heating value of stalks or wood wastes is only about half of the conventional coal fuel, and scattered distribution of resources, they are difficult to collect and transport at low cost. Moreover, in order to meet the requirement of feedstock for the gasification process, it is necessary to add equipment for biomass pretreatment, such as drying and crash, etc. Subsequently, the operation cost of biomass gasification power generation station increases for these reasons. Presently, biomass electricity generation can withstand biomass feedback cost up to $250 \mathrm{RMB} / \mathrm{t}$, but the actual cost usually matches or even exceeds this value.

Gas engine systems are widely used for biomass gasification power generation in China now. Since the unit capacity utilized is mainly $200-400 \mathrm{~kW}$, multi-units are required for application, e.g. a $2 \mathrm{MW}$ power system will be equipped with 5-10 units, which causes more land occupation and harder management. This characteristic does not adapt to large-scale application of the technology, and larger units are being researched.

Tar produced in the biomass gasification process is a serious problem to biomass gas power generation because it can block pipes, contaminate the cylinder and then disturb the running of generating equipment. At present, the main idea is to crack the tar into small molecular gases, such as $\mathrm{H}_{2}$, $\mathrm{CO}$, etc., by high temperature thermal cracking or catalytic cracking. High temperature thermal cracking method is difficult for actual use because a high temperature of about $1100{ }^{\circ} \mathrm{C}$ is required for operation. Catalytic cracking based on catalysts like nickel, charcoal or dolomite requires lower temperature. Nickel based catalysts have good catalytic cracking effect at $750{ }^{\circ} \mathrm{C}$, but are too expensive to obtain. Charcoal and dolomite are easy to get but their catalytic effects are relatively weak. At present, hard work on the problem is being conducted for practical applications.

\section{Biomass electricity price in China}

Economy is the most important criterion for the development of biomass gasification power generation. Like other renewable energies, the cost of biomass electricity is far beyond that of fossil energy. However, apart from the cost, another key factor of economy is the government subsidy policies.

China's landmark "Renewable Energy Law" took effect in 2006. According to the corresponding regulations of the law, there was a universal $0.25 \mathrm{RMB} / \mathrm{kWh}$ subsidy to the renewable power price all over China. By adding this subsidy to the benchmark on-grid price, biomass power price in China was around 0.6 RMB/kWh, still lower than the cost of most biomass power stations. To save the enterprises of this industry from losses, the government unified the biomass electricity price at $0.75 \mathrm{RMB} / \mathrm{kWh}$. However, since the "Renewable Energy Law" was issued, raw biomass material prices have increased to different degrees all over the country. Moreover, fossil fuel prices affected biomass material prices as well. The transportation cost doubled since 2005 due to higher fuel costs, and other costs, such as labor and equipment, also increased a lot due to the economic growth.

A comparison of costs before and after the issue of "Renewable Energy Law" is shown in Table 8. It can be told that the direct electricity generation cost upswung from $0.37 \mathrm{RMB} / \mathrm{kWh}$ to $0.56 \mathrm{RMB} / \mathrm{kWh}$, with a growth of $51.4 \%$. Among all the sub-costs, raw materials grew the fastest, and contributed $70 \%$ to the total cost. Though other costs, like labor and operation, somehow rose in recent years, the rapid rise of biomass material cost is the major cause for increasing cost of biomass power generation, therefore resulting in losses of biomass power projects these years under the electricity price compensation mechanism. If the raw material cost cannot be effectively controlled, the electricity cost, though supported with subsidies, will go up accordingly and finally lose its advantage in future competition.

\section{Prospect}

In the national energy conference in 2010, the director of national energy administration put forward "Overall Requirements and Major Tasks for the Energy Work in 2010". In this report, three tasks about biomass utilization were set forth: standardizing the project management of biomass power generation and keeping the existing biomass power station in good operation; developing more biomass gasification and briquette programs in rural areas; and strengthening the rural energy construction. Thus it can be seen here that gasification will play an important role in the future in China.

\section{Table 8}

Cost variation before and after the issue of "Renewable Energy Law" of the $6 \mathrm{MW}$ biomass gasification power generation project.

\begin{tabular}{rllll}
\hline \multirow{2}{*}{ No. } & Content & Unit & Time & \\
\cline { 4 - 5 } & & & Before 2005 & After 2006 \\
\hline \multirow{2}{n}{1} & Capacity & $\mathrm{kW}$ & 6000 & 6000 \\
2 & Running time & $\mathrm{h} / \mathrm{yr}$ & 6500 & 6500 \\
3 & Self-power consumption & $\%$ & 8 & 8 \\
4 & Power for sale & $10^{4} \mathrm{kWh} / \mathrm{yr}$ & 3588 & 3588 \\
5 & Biomass consumption & $\mathrm{kg}(\mathrm{dry}) / \mathrm{kWh}$ & 1.25 & 1.25 \\
6 & Water content & $\%$ & 15 & 15 \\
7 & Biomass price & $\mathrm{RMB} / \mathrm{t}$ & 170 & 270 \\
8 & Biomass consumption & $\mathrm{t} / \mathrm{yr}$ & 67,474 & 67,474 \\
9 & Biomass cost & $10^{6} \mathrm{RMB} / \mathrm{yr}$ & 9.75 & 15.49 \\
10 & Labor cost & $10^{6} \mathrm{RMB} / \mathrm{yr}$ & 1.5 & 1.8 \\
11 & Operating cost & $10^{6} \mathrm{RMB} / \mathrm{yr}$ & 2.0 & 2.85 \\
12 & Total cost & $10^{6} \mathrm{RMB} / \mathrm{yr}$ & 13.25 & 20.14 \\
13 & Direct electricity cost & $\mathrm{RMB} / \mathrm{kWh}$ & 0.37 & 0.56 \\
\hline
\end{tabular}


Biomass gasification power generation technologies are flexible, with a scale that could vary from several $\mathrm{kW}$ to $10 \mathrm{MW}$. The relatively small radius to gather biomass materials guarantees a stable biomass supply; the strong adaptability for raw materials ensures economic feasibility under different scale levels; its producing process makes biomass gasification power generation suitable for distributed resources. All aforementioned advantages give it a bright prospect in China. In today's macro-background of lowcarbon and energy saving, demonstration projects have been established by several companies and institutes specializing in this field. Although the total capacity is not large( less than $100 \mathrm{MW}$ ), these demonstrations still play an active role in the industrial development of biomass gasification power generation in China.

Due to a rich coal reserve, coal-based electricity will retain its dominance in China for a long term. Power generation from biomass gasification is on a relatively small scale and would best be used as a supplementary power, and is suitable for remote rural regions far from the grid which are short of electricity. For the abundant recourse of crop stalks in China, it can be either converted to high grade electric energy through gasification or used to produce liquid fuel. Though the conversion of cellulosic biomass to liquid fuel is not mature now, in the long run it seems more practically valuable to substitute petroleum-based fuel when the technology is well developed. It is expected that the liquid fuel technology breakthrough will be made about ten years later, and at that time the power generation from crop stalks may be affected to some extent.

\section{Acknowledgments}

This research is funded by CAS project of Key Technology Research and Demonstration of Biomass Gasification and Synthesis and Power Generation System (Grant no. KGCX2-YW-329), and Key Projects in the National Science and Technology Pillar Program (Grant no. 2011BAD22B06).

\section{References}

Dai, L., Li, Z.L., Xin, Q.Z., Gao, X.W., 2004. Development of 8300DM Biomass Gasification Engine. Diesel Engine 5, 4-6.

De Lange, Barbucci, 1998. The THERMIE energy farm project. Biomass and Bioenergy 15 (3), 219-224.

ESPOO, 2002. Review of Finish Biomass Gasification Technologies. OPET Report 4 Technical Research Centre of Finland.

Keith, P., Barbara, H., Henrik, L., 1998. The ARBRE project progress achieved. Biomass and Bioenergy 15 (3), 213-218.

Krister, S., Lars, W., Michael, M., Ulf, J., Lennart, G., 2004. Biomass IGCC at Värnamo. GCEP Energy Workshop, Sweden-Past and future.

Liao, C.P., Wu, C.Z., Yan, Y.J., 2007. The characteristics of inorganic elements in ashes from a $1 \mathrm{MW}$ CFB biomass gasification power generation plant. Fuel Processing Technology 88 (2), 149-156.

Ma, L.L., Yan, Y.J., Wu, C.Z., Li, T.C., Marzetti, P., Scoditti, E., Braccio, G., 2008. The design and operation of a new clapboard-type internal circulating fluidizedbed gasifier. Energy Sources, Part A 30, 1563-1571.

Wu, C.Z., Yin, X.L., Ma, L.L., Zhou, Z.Q., Chen, H.P., 2009. Operational characteristics of a 1.2-MW biomass gasification and power generation plant. Biotechnology Advances 27 (5), 588-592.

Wu, C.Z., Huang, H.T., Zheng, S.P., Yin, X.L., 2002. An economic analysis of biomass gasification and power generation in China. Bioresource Technology 83 (1), 65-70.

Yin, X.L., Wu, C.Z., Zheng, S.P., Chen, Y., 2002. Design and operation of a CFB gasification and power generation system for rice husk. Biomass and Bioenergy 23 (3), 181-187. 